Pacific Journal of Mathematics

AN INEQUALITY FOR LOGARITHMIC CAPACITIES 


\section{AN INEQUALITY FOR LOGARITHMIC CAPACITIES}

\section{HEINZ RENGGLI}

1. Introduction. In his work on capacities, G. Choquet proved that for many capacities the inequality of strong subadditivity holds [1]. It is the purpose of this note to show that a similar inequality holds for logarithmic capacities. More precisely we shall prove the

THEOREM. Let $A$ and $B$ be compact sets in the complex $z$-plane $E$. $B y C(S)$ we denote the logarithmic capacity [2] of a given compact set $S, S \subset E$, where we agree to put $C(S)=0$ whenever $S=\phi$. Then

$$
C(A \cup B) \cdot C(A \cap B) \leqq C(A) \cdot C(B) .
$$

2. Proof of the theorem. Let $S, S \subset E$, be a compact set whose boundary consists of a finite number of analytic arcs. By $S^{*}$ we denote that component of $E-S$ which is unbounded. Then Green's function of $S^{*}$ is defined by the properties: it is harmonic in $S^{*}$, vanishes at the finite boundary points of $S^{*}$ and has a logarithmic singularity at infinity. We will denote this function by $g_{S}(z, \infty)$.

First we shall deal with the case when the respective boundaries of $A, B$ and $A \cap B$ consist of a finite number of non-degenerate analytic arcs. We remark that the difference $g_{A \cap B}(z, \infty)-g_{A}(z, \infty)$ is harmonic in $A^{*}, A^{*} \subset(A \cap B)^{*}$, and at infinity. It is furthermore non-negative on the boundary of $A^{*}$ and hence non-negative in $A^{*}$ by the maximum principle. Similarly $g_{A \cup B}(z, \infty) \geqq g_{B}(z, \infty)$ holds in $B^{*}, B^{*} \subset(A \cap B)^{*}$.

The function

$$
h(z)=g_{A \cup B}(z, \infty)+g_{A \cap B}(z, \infty)-g_{A}(z, \infty)-g_{B}(z, \infty)
$$

is harmonic in $(A \cup B)^{*}$ and at infinity. From $(A \cup B)^{*}=A^{*} \cap B^{*}$ it follows that the boundary points of $(A \cup B)^{*}$ belong either to the boundary of $A^{*}$ or to the boundary of $B^{*}$. Therefore $g_{A \cup B}(z, \infty)$ and either $g_{A}(z, \infty)$ or $g_{B}(z, \infty)$ vanish at these boundary points. With the aid of the remark made above we get the result that $h(z)$ is non-negative in $(A \cup B)^{*}$.

Therefore

$$
g_{A}(z, \infty)+g_{B}(z, \infty) \leqq g_{A \cup B}(z, \infty)+g_{A \cap B}(z, \infty)
$$

holds in $(A \cup B)^{*}$. From this general inequality and using the fact that

Received December 16, 1959. Presented to the Amer. Math. Soc. in Jan. 1958, where a less elementary proof based on an inequality for extremal lengths was given. 


$$
\lim _{z \rightarrow \infty}\left\{g_{S}(z, \infty)-\log |z|\right\}
$$

is the constant $\gamma(S)$ of Robin [2] we deduce

$$
\gamma(A)+\gamma(B) \leqq \gamma(A \cup B)+\gamma(A \cap B) .
$$

But

$$
C(S)=\exp \{-\gamma(S)\}
$$

by definition. Hence our theorem is proven for the special case.

The general case follows by the usual approximation techniques [2].

\section{REFERENCES}

1. G. Choquet, Theory of capacities, Ann. Inst. Fourier, Grenoble 5 (1953-54), 131-295.

2. R. Nevanlinna, Eindeutige analytische Funktionen, Grundlehren 46, 2. Aufl., Springer, 1953.

RUTGERS UNIVERSITY 


\section{PACIFIC JOURNAL OF MATHEMATICS}

\section{EDITORS}

Ralph S. Phillips

Stanford University

Stanford, California

F. H. BrownelL

University of Washington

Seattle 5 , Washington
A. L. Whiteman

University of Southern California Los Angeles 7. California

L. J. PAIGE

University of California

Los Angeles 24, California

ASSOCIATE EDITORS
E. F. BECKENBACH
D. DERRY
H. L. ROYDEN
E. G. STRAUS
T. M. CHERRY
M. OHTSUKA
E. SPANIER
F. WOLF

\section{SUPPORTING INSTITUTIONS}

UNIVERSITY OF BRITISH COLUMBIA

CALIFORNIA INSTITUTE OF TECHNOLOGY

UNIVERSITY OF CALIFORNIA

MONTANA STATE UNIVERSITY

UNIVERSITY OF NEVADA

NEW MEXICO STATE UNIVERSITY

OREGON STATE COLLEGE

UNIVERSITY OF OREGON

OSAKA UNIVERSITY

UNIVERSITY OF SOUTHERN CALIFORNIA
STANFORD UNIVERSITY

UNIVERSITY OF TOKYO

UNIVERSITY OF UTAH

WASHINGTON STATE COLLEGE,

UNIVERSITY OF WASHINGTON

AMERICAN MATHEMATICAL SOCIETY

CALIFORNIA RESEARCH CORPORATION

HUGHES AIRCRAFT COMPANY

SPACE TECHNOLOGY LABORATORIES

NAVAL ORDNANCE TEST STATION

Printed in Japan by International Academic Printing Co., Ltd., Tokyo, Japan

Reprinted 1966 in the United States of America 


\section{Pacific Journal of Mathematics}

\section{Vol. 11, No. $1 \quad$ November, 1961}

A. A. Albert, Generalized twisted fields ............................ 1

Richard Arens, Operational calculus of linear relations ................... 9

John Herbert Barrett, Disconjugacy of a self-adjoint differential equation of the fourth order ....................................... 25

Paul Richard Beesack, Hardy's inequality and its extensions ............... 39

Julius Rubin Blum and David Lee Hanson, On invariant probability measures.

II .............................................

Robert Allen Bonic, Symmetry in group algebras of discrete groups.......... 73

R. Creighton Buck, Multiplication operators ...................... 95

Jack Gary Ceder, Some generalizations of metric spaces ................. 105

Meyer Dwass, Random crossings of cumulative distribution functions ......... 127

Albert Edrei, Wolfgang H. J. Fuchs and Simon Hellerstein, Radial distribution and

deficiencies of the values of a meromorphic function ............... 135

William Cassidy Fox, Harmonic functions with arbitrary local singularities ..... 153

Theodore Thomas Frankel, Manifolds with positive curvature ............... 165

Avner Friedman, A strong maximum principle for weakly subparabolic

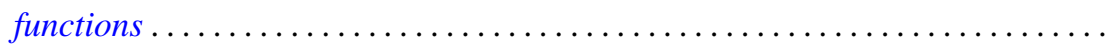

Watson Bryan Fulks and J. O. Sather, Asymptotics. II. Laplace's method for

multiple integrals ......................................

Adriano Mario Garsia and Eugene Richard Rodemich, An embedding of Riemann

surfaces of genus one ..................................... 193

Irving Leonard Glicksberg, Weak compactness and separate continuity......... 205

Branko Grünbaum, On a conjecture of H. Hadwiger .................. 215

Frank J. Hahn, On the action of a locally compact group on $E_{n} \ldots \ldots \ldots \ldots \ldots . . \ldots 221$

Magnus R. Hestenes, Relative hermitian matrices ..................... 225

G. K. Kalisch, On similarity invariants of certain operators in $L_{p} \ldots \ldots \ldots \ldots .247$

Yitzhak Katznelson and Walter Rudin, The Stone-Weierstrass property in Banach

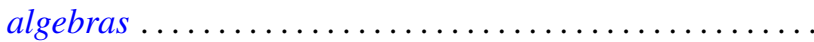

Samir A. Khabbaz, The subgroups of a divisible group $G$ which can be represented as intersections of divisible subgroups of $G \ldots \ldots \ldots \ldots \ldots \ldots \ldots \ldots \ldots . \ldots \ldots 7$

Marvin Isadore Knopp, Construction of a class of modular functions and forms .......................................... 275

Charles Alan McCarthy, Commuting Boolean algebras of projections .......... 295

T. M. MacRobert, Transformations of series of E-functions ................ 309

Heinz Renggli, An inequality for logarithmic capacities ................. 313

M. S. Robertson, Applications of the subordination principle to univalent functions .......................................... 315

David Sachs, Partition and modulated lattices ..................... 325

Frank S. Scalora, Abstract martingale convergence theorems ............... 347

Elbert A. Walker, Torsion endomorphic images of mixed Abelian groups ........ 375

Morgan Ward, The prime divisors of Fibonacci numbers................. 379

Charles R. B. Wright, On the nilpotency class of a group of exponent four....... 387 